\title{
Effect of rofecoxib on platelet aggregation and blood loss in gynaecological and breast surgery compared with diclofenac
}

\author{
T. R. Hegi ${ }^{1}$, T. Bombeli ${ }^{2}$, B. Seifert ${ }^{3}$, P. C. Baumann ${ }^{4}$, U. Haller ${ }^{5}$, M. P. Zalunardo ${ }^{1}$, \\ T. Pasch ${ }^{1}$ and D. R. Spahn'
}

${ }^{1}$ Institute of Anaesthesiology, University Hospital of Zurich, Rämistrasse 100, CH-8091 Zürich, Switzerland.

${ }^{2}$ Division of Hematology, Department of Internal Medicine, University Hospital of Zurich,

Rämistrasse 100, CH-8091 Zürich, Switzerland. ${ }^{3}$ Department of Biostatistics, ISPM,

University of Zurich, Sumatrastrasse 30, CH-8006 Zürich, Switzerland. ${ }^{4}$ Institute of Anaesthesiology,

Intensive Care Unit, Kantonsspital Zug, Artherstrasse 27, CH-6300 Zug, Switzerland.

${ }^{5}$ Department of Gynaecology, University Hospital of Zurich, Rämistrasse 100, CH-8091 Zürich, Switzerland.

${ }^{6}$ Institute of Anaesthesiology, University Hospital of Lausanne, Rue du Bugnon 46, CH-1011 Lausanne,

Switzerland

*Corresponding author. E-mail: thomas.hegi@usz.ch

Background. Non-selective cyclooxygenase (COX) inhibitors or non-steroidal antiinflammatory drugs (NSAIDs) are frequently omitted for perioperative pain relief because of potential side-effects. COX-2-selective inhibitors may have a more favourable side-effect profile. This study tested the hypothesis that the COX-2-selective inhibitor rofecoxib has less influence on platelet function than the NSAID diclofenac in gynaecological surgery. In addition, analgesic efficacy and side-effects of the two drugs were compared.

Methods. In this single-centre, prospective, double-blind, active controlled study, women undergoing vaginal hysterectomy $(n=25)$ or breast surgery $(n=25)$ under general anaesthesia received preoperatively $50 \mathrm{mg}$ of rofecoxib p.o. followed 8 and $16 \mathrm{~h}$ later by two doses of placebo or three doses of diclofenac $50 \mathrm{mg}$ p.o. at the same time points. We assessed arachidonic acid-stimulated platelet aggregation before and $4 \mathrm{~h}$ after the first dose of study medication, estimated intraoperative blood loss, and haemoglobin loss until the first morning after surgery. Analgesic efficacy, use of rescue analgesics, and side-effects were also recorded.

Results. In the rofecoxib group, stimulated platelet aggregation was disturbed less $(P=0.02)$, and estimated intraoperative blood loss $(P=0.0 \mathrm{I})$ and the decrease in haemoglobin were lower $(P=0.01)$. At similar pain ratings, the use of anti-emetic drugs was less in the rofecoxib group $(P=0.03)$.

Conclusion. Besides having a smaller effect on platelet aggregation, one oral dose of rofecoxib $50 \mathrm{mg}$ given before surgery provided postoperative analgesia similar to that given by three doses of diclofenac $50 \mathrm{mg}$ and was associated with less use of anti-emetics and less surgical blood loss in gynaecological surgery compared with diclofenac.

BrJ Anaesth 2004; 92: 523-31

Keywords: analgesia, postoperative; analgesics non-opioid, diclofenac; analgesics non-opioid, rofecoxib; antagonists, cyclooxygenase type 2 antagonist; blood, platelet aggregation, drug effects; non-steroidal anti-inflammatory drugs

Accepted for publication: November 24, 2003 
Perioperative use of non-steroidal anti-inflammatory drugs (NSAIDs) reduces postoperative pain ${ }^{1}$ and opioid consumption $^{2}$ but may be associated with side-effects. ${ }^{3-5}$ Cyclooxygenase-2 (COX-2)-selective inhibitors represent an alternative treatment with a more favourable side-effect profile, including less effect on platelet function ${ }^{6}$ and the gastrointestinal tract. ${ }^{7}$ The perioperative use of COX-2 inhibitors, however, is not yet established.

We therefore performed this double-blind, active controlled study to assess the effect of rofecoxib $50 \mathrm{mg}$ compared with three oral doses of diclofenac $50 \mathrm{mg}$ on platelet aggregation and other parameters of blood coagulation in gynaecological surgery. In addition, we compared efficacy, intraoperative blood loss, loss of haemoglobin, consumption of analgesics, renal function, and other sideeffects.

\section{Patients and methods}

The study was approved by the Ethical Committee of the University Hospital Zurich and conducted in accordance with the principles of the Declaration of Helsinki. All patients enrolled in the study gave written informed consent.

This single-centre, double-blinded, active controlled study was conducted on 50 female patients (29-74 yr) who underwent surgery in the Department of Gynaecology, University Hospital of Zurich, Switzerland. No placebo group was included as exclusion of patients from standard analgesic treatment was deemed ethically inappropriate. Two sets of patients were studied in parallel: 25 patients scheduled for vaginal hysterectomy and 25 patients undergoing surgery for suspected breast cancer. The hysterectomy group was included to allow measurement of creatinine clearance, as only these patients are routinely instrumented with a bladder catheter. Patients were excluded if they had a history of gastrointestinal bleeding or gastric, duodenal or oesophageal ulceration; Crohns' disease, ulcerative colitis or liver disease; aspartate transaminase or alanine transaminase concentrations above twice upper normal values; hepatic porphyria; serum creatinine above $105 \mu \mathrm{mol}$ litre $^{-1}$; history of bronchial asthma, intracranial bleeding within the last 6 months, pregnancy or breastfeeding; history of bleeding disorders, prolonged prothrombin time, platelet count below 150000 $\mathrm{mm}^{-3}$, anticoagulant therapy, received acetylsalicylic acid within the last 7 days, NSAID therapy within $48 \mathrm{~h}$, opioid treatment within $72 \mathrm{~h}$ before surgery or immunosuppressants, including corticosteroids, anti-epileptics or nephrotoxic drugs; or hypersensitivity to one of the study drugs or anaesthetics.

Patients in both surgical subsets were block-randomized into the diclofenac or rofecoxib group using a computergenerated table. The study medication was prepared by the hospital pharmacy. Placebo capsules were filled with lactose and were indistinguishable from the active treatment. All persons involved in the conduct of the study and the patients were blinded regarding the group assignment. After oral premedication with midazolam 3.75 or $7.5 \mathrm{mg}$, blood specimens were taken for coagulation tests when the patient arrived in the operating theatre.

In the diclofenac group subjects received $50 \mathrm{mg}$ diclofenac sodium $\left(\right.$ Voltaren $^{\circledR}$; Novartis, Bern, Switzerland) orally just before anaesthesia induction, followed by $50 \mathrm{mg} 8$ and $16 \mathrm{~h}$ later. In the rofecoxib group, rofecoxib $50 \mathrm{mg}\left(\mathrm{Vioxx}^{\circledR}\right.$; MSD, Glattbrugg, Switzerland) was administered orally just before anaesthesia induction, followed by placebo 8 and $16 \mathrm{~h}$ later. A standardized general anaesthetic technique was used for induction (propofol $1.5-2.5 \mathrm{mg} \mathrm{kg}^{-1}$, fentanyl $2 \mu \mathrm{g} \mathrm{kg}^{-1}$, rocuronium bromide $0.6 \mathrm{mg} \mathrm{kg} \mathrm{kg}^{-1}$ ) and maintenance (propofol 4-10 $\mathrm{mg} \mathrm{kg}^{-1} \mathrm{~h}^{-1}$, one dose of fentanyl $2 \mu \mathrm{g}$ $\mathrm{kg}^{-1}$ before skin incision). The use of propofol, remifentanil and nicomorphine was left to the discretion of the anaesthetist and the doses given were recorded. (Nicomorphine is an opioid with the same potency as morphine.) Before the end of surgery, tropisetron $2 \mathrm{mg}$ was administered to all patients to prevent postoperative nausea and vomiting (PONV). In the recovery room patients received nicomorphine i.v. according to their needs. Before the patients were transferred to the ward, patientcontrolled analgesia (PCA) was started (nicomorphine, initial setting $1 \mathrm{mg}$ bolus dose, $5 \mathrm{~min}$ lockout time, no basal infusion rate). PCA settings were changed according to the needs of the patient.

Patients were assessed at four specific time points: 1 and $4 \mathrm{~h}$ after emergence, and $8 \mathrm{~h}$ and $24 \mathrm{~h}$ after the first dose of the study medication. Pain was evaluated using the visual analog scale (VAS, $0 \mathrm{~mm}=$ no pain, $100 \mathrm{~mm}=$ worst pain imaginable). PONV was rated using a four-item scale ( $1=$ no nausea, 2=nausea, 3=vomiting, 4=intractable vomiting). The administered doses of the rescue anti-emetics (tropisetron $2 \mathrm{mg}$ i.v. and dihydrobenzperidol $1.25 \mathrm{mg}$ i.v.) were recorded. The following variables and side-effects were also recorded: heart rate, systolic and diastolic blood pressures, use of nicomorphine or rescue analgesics, other side-effects regarding the gastrointestinal tract, sedation and headache. Other events, e.g. increased bleeding, need for further surgery and haematemesis, were recorded throughout the $24 \mathrm{~h}$ observation period.

Pain scores were assessed by patients at 8 and 24 h using a five-item categorical verbal rating scale (VRS) (1=poor, 2=moderate, 3=good, 4=very good, 5=excellent). ${ }^{8}$ Similarly, patients were asked to rate their satisfaction with respect to PONV on a five-item categorical VRS at 8 and $24 \mathrm{~h}$ (1=poor, 2=moderate, 3=good, 4=very good, $5=$ excellent).

The surgeon estimated intraoperative blood loss in millilitres, and the activity of the coagulation system using a five-item scale (1=no coagulation, $2=$ poor, $3=$ moderate, 4=good, 5=increased coagulation). According to standard practice, all patients received low molecular weight heparin dalteparine sodium 2500 IU s.c. at 6 p.m. 
Table 1 (A) Patient characteristics and surgical and anaesthesiological data in the intent-to-treat population ( $n=50)$. Data are mean (range) for age or mean (SD). *Uneven distribution of the three types of breast surgery between the two drug groups $(P=0.01)$. (B) Patient characteristics and surgical, and anaesthesiological data for the subgroup $(n=38)$ (excluding, abdominal hysterectomy, minor breast surgery and mastectomy patients). Data are mean (range) for age or mean (SD). There were no significant differences between the two drug and surgery groups

\begin{tabular}{|c|c|c|c|c|}
\hline \multirow[t]{2}{*}{ (A) } & \multicolumn{2}{|l|}{ Rofecoxib } & \multicolumn{2}{|l|}{ Diclofenac } \\
\hline & Hysterectomy & Breast surgery & Hysterectomy & Breast surgery \\
\hline Number $(n)$ & 13 & 12 & 12 & 13 \\
\hline Vaginal/transabdominal hysterectomy & $1 / 12$ & - & $2 / 10$ & - \\
\hline Lumpectomy/tumour and axilla dissection/mastectomy & - & $5 / 7 / 0$ & - & $0 / 9 / 4 *$ \\
\hline ASA I/II/III & $5 / 8 / 0$ & $7 / 5 / 0$ & $9 / 3 / 0$ & $5 / 7 / 1$ \\
\hline Age (yr) & $53(39-73)$ & $48(29-70)$ & $49(36-74)$ & $53(36-67)$ \\
\hline Height $(\mathrm{cm})$ & $163(7)$ & $166(6)$ & $163(7)$ & $166(4)$ \\
\hline Weight $(\mathrm{kg})$ & $69(11)$ & $62(9)$ & $66(10$ & $65(10)$ \\
\hline Haemoglobin baseline $\left(\mathrm{g} \mathrm{litre}^{-1}\right)$ & $130(10)$ & $126(7)$ & $123(9)$ & $134(10)$ \\
\hline Serum creatinine baseline $\left(\mathrm{mmol}\right.$ litre $\left.^{-1}\right)$ & $77(11)$ & $81(10)$ & $80(15)$ & $80(13)$ \\
\hline Cystatin c baseline (mg litre $\left.{ }^{-1}\right)$ & $1.01(0.21)$ & $0.99(0.14)$ & $1.00(0.33)$ & $1.03(0.15)$ \\
\hline Anaesthesia duration (min) & $184(61)$ & $141(50)$ & $168(74)$ & $197(53)$ \\
\hline Operation duration (min) & $136(65)$ & $93(44)$ & $124(66)$ & $134(53)$ \\
\hline Propofol, total dose (mg) & $1432(423)$ & $1018(56) 3$ & $1299(514)$ & $1331(390)$ \\
\hline Remifentanil, mean intraoperative rate $\left(\mu \mathrm{g} \mathrm{kg}^{-1} \min ^{-1}\right)$ & $0.14(0.09)$ & $0.08(0.07)$ & $0.12(0.13)$ & $0.13(0.06)$ \\
\hline \multirow[t]{2}{*}{ (B) } & \multicolumn{2}{|l|}{ Rofecoxib } & \multicolumn{2}{|l|}{ Diclofenac } \\
\hline & Hysterectomy & Breast surgery & Hysterectomy & Breast surgery \\
\hline Number $(n)$ & 12 & 7 & 10 & 9 \\
\hline Vaginal hysterectomy & 12 & - & 10 & - \\
\hline Tumor and axilla dissection & - & 7 & - & 9 \\
\hline ASA I/II/III & $4 / 8 / 0$ & $2 / 5 / 0$ & $7 / 3 / 0$ & $3 / 5 / 1$ \\
\hline Age $(y r)$ & $55(42-73)$ & $55(44-70)$ & $50(36-74)$ & $56(42-67)$ \\
\hline Height $(\mathrm{cm})$ & $163(7)$ & $165(6)$ & $163(6)$ & $167(4)$ \\
\hline Weight $(\mathrm{kg})$ & $68(11)$ & $62(10)$ & $66(10)$ & $66(11)$ \\
\hline Haemoglobin baseline $\left(\mathrm{g} \mathrm{litre}^{-1}\right)$ & $131(10)$ & $127(8)$ & $125(8)$ & $134(11)$ \\
\hline Serum creatinine baseline ( $\mathrm{mmol}$ litre $^{-1}$ ) & $78(11)$ & $78(7)$ & $77(15)$ & $80(15)$ \\
\hline Cystatin- $\mathrm{C}$ baseline $\left(\mathrm{mg}\right.$ litre $\left.^{-1}\right)$ & $1.02(0.22)$ & $1.02(0.12)$ & $0.99(0.36)$ & $1.07(0.16)$ \\
\hline Anaesthesia duration (min) & $185(63)$ & $176(28)$ & $178(78)$ & $207(58)$ \\
\hline Operation duration (min) & $138(67)$ & $121(28)$ & $132(69)$ & $144(60)$ \\
\hline Propofol, total dose (mg) & $1442(440)$ & $1334(494)$ & $1319(552)$ & $1452(394)$ \\
\hline Remifentanil, mean intraoperative rate $\left(\mu \mathrm{g} \mathrm{kg}^{-1} \min ^{-1}\right)$ & $0.15(0.09)$ & $0.12(0.04)$ & $0.13(0.13)$ & $0.14(0.07)$ \\
\hline
\end{tabular}

daily, starting the evening before surgery. Citrated blood for the coagulation studies was sampled just before the administration of the trial drug and again $4 \mathrm{~h}$ later. Platelet function was assessed by classical platelet aggregometry according to Born, using an automated platelet aggregation coagulation tracer (APACT; Labor, Hamburg, Germany). All measurements were performed in plateletrich plasma using arachidonic acid (2 mmol litre $^{-1}$ ), collagen $\left(5 \mathrm{mmol} \mathrm{litre}^{-1}\right)$ and ADP $\left(5 \mu \mathrm{mol} \mathrm{litre}{ }^{-1}\right)$ as aggregation inducers. To additionally determine the degree of inhibition of arachidonic acid metabolism of the platelets, the malondialdehyde (MDA) content of the platelets was determined as described previously. ${ }^{9}$ MDA is produced by the degradation of prostaglandin $\mathrm{H}_{2}$, which is a product of the COX-1-mediated degradation of arachidonic acid. Inhibition of COX-1 results in decreased concentrations of MDA.

The Thrombelastograph Coagulation Analyzer (CTEG 3000; Haemoscope, Morton Grove, IL, USA) with $1 \%$ celite activation was used, and the blood was recalcified and processed $1 \mathrm{~h}$ after collection as described earlier. ${ }^{10}$ The following parameters of the thrombelastograph $\left(\mathrm{TEG}^{\circledR}\right)$ trace were analysed: reaction time $(\mathrm{r})$, coagulation time $(\mathrm{k})$, maximum amplitude (MA), angle $(\alpha)$ and clot lysis 30 (Ly30) $30 \mathrm{~min}$ after reaching MA. Kidney function was assessed using serum creatinine and cystatin $\mathrm{c}^{11}$ both before the operation and at $24 \mathrm{~h}$. In addition, in patients undergoing hysterectomy creatinine clearance was measured from the end of surgery until $24 \mathrm{~h}$. A set of standard clinical laboratory tests, including haemoglobin, was performed not earlier than $72 \mathrm{~h}$ before induction of anaesthesia and at $24 \mathrm{~h}$.

The primary outcome variable was platelet aggregation stimulated with arachidonic acid. Calculations of the necessary sample size were done according to our own preliminary data and the work of Leese and colleagues. ${ }^{6}$ The inclusion of 18 patients in each drug group was determined to yield $90 \%$ power to detect a reduction of $40 \%$ in 
reactivity of platelet aggregation after arachidonic acid, taking into account a standard deviation of $25 \%$ and a twosided $t$-test with a significance level of 0.05 .

Secondary outcome variables were blood loss during operation, haemoglobin loss, VAS for pain, nicomorphine consumption, use of rescue anti-emetics, PONV ratings, and decreases in the parameters of the function of the kidney.

\section{Statistical analysis}

The drug groups were compared for patients from both types of surgery using two-way factorial ANOVA. When the same variable was analysed at different time points, Bonferroni correction was applied. Effect size is presented as the mean difference with the $95 \%$ confidence interval (CI). Data were transformed where appropriate to an approximate normal distribution. For transformed data, the standardized effect size (mean difference divided by standard deviation) with $95 \% \mathrm{CI}$ is shown. For categorical data, logistic regression was used. All tests were two-sided, and $P$ values less than 0.05 were considered statistically significant.

\section{Results}

\section{Patients}

Fifty patients, with a median age of $48 \mathrm{yr}$, were enrolled in the study; all were followed until $24 \mathrm{~h}$. In the hysterectomy group the surgical technique was changed during the procedure in three of the 25 patients because of technical difficulties with a transvaginal approach to hysterectomy via laparotomy (two subjects in the diclofenac group, one subject in the rofecoxib group). These three patients had more pain $1 \mathrm{~h}$ after emergence and a greater need for nicomorphine until $24 \mathrm{~h}$ than the rest of the group (unpaired $t$-test, $P<0.05)$. In the breast surgery group, three types of operation were performed; removal of a benign lesion, tumour resection with dissection of the axilla, and mastectomy. Despite randomization, there was an unequal distribution of these three types of surgery between the two drug groups. While all four mastectomy patients were randomized to the diclofenac group, all five patients with benign lesions and lumpectomy were randomized to the rofecoxib group (Mann-Whitney test, $P<0.01$ ). In two patients, the $16 \mathrm{~h}$ study medication was not given because of nausea (breast surgery, rofecoxib group) and vomiting (hysterectomy, diclofenac group). Two further patients received a rescue analgesic of propyphenazone $125 \mathrm{mg}$ and dihydroergotamine $0.5 \mathrm{mg}$ according to the study protocol at 20 $\mathrm{h}$ (hysterectomy, diclofenac group) and $18 \mathrm{~h}$ (breast surgery, rofecoxib group) for headache during the night after surgery.

In an intention-to-treat analysis, all 50 patients were included in the evaluation. The results were then controlled by analysing the subgroup $(n=38)$ including the vaginal

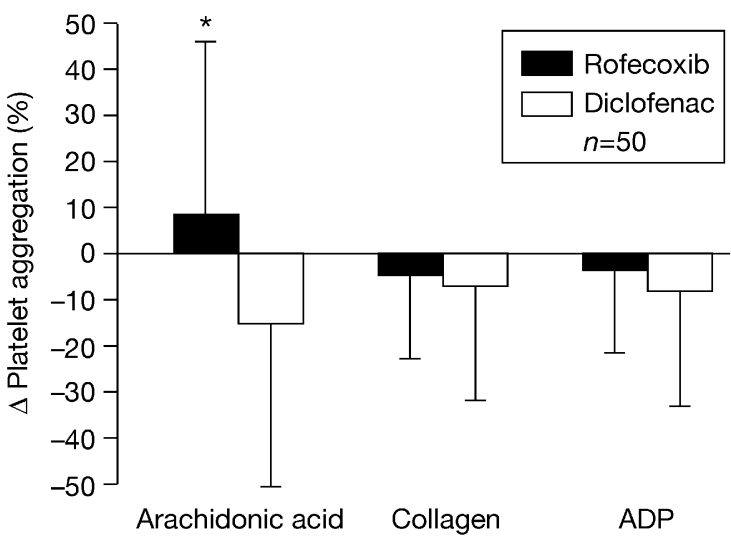

Fig 1 Platelet aggregation stimulated with arachidonic acid $2 \mathrm{mmol}$ litre $^{-1}$, collagen $5 \mathrm{mmol}$ litre $^{-1}$ and ADP $5 \mu \mathrm{mol} \mathrm{litre}{ }^{-1}$. Data are for all patients $(n=50)$, and show the measurement $4 \mathrm{~h}$ after the first study drug minus the value measured immediately before the first dose of the study drug. Values are mean and SD. Two-way factorial ANOVA. ${ }^{*} P=0.02$ vs diclofenac.

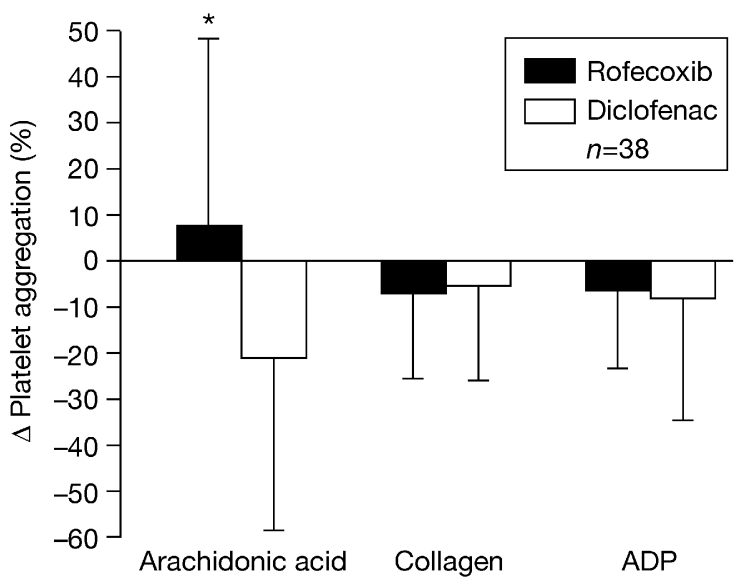

Fig 2 Platelet aggregation stimulated with arachidonic acid $2 \mathrm{mmol}$ litre $^{-1}$, collagen $5 \mathrm{mmol}$ litre ${ }^{-1}$ and ADP $5 \mu \mathrm{mol}$ litre $^{-1}$. Data are for the subgroup ( $n=38)$ and show the measurement $4 \mathrm{~h}$ after the first study drug minus the value measured immediately before the first dose of the study drug. Values are mean and SD. Two-way factorial ANOVA. $* P=0.01$ vs diclofenac.

hysterectomy $(n=22)$ and tumour with axilla dissection patients only $(n=16)$.

The two drug and surgical groups $(n=50)$ were comparable with respect to ASA physical status, age, weight, height, baseline values of haemoglobin, markers of kidney function, duration of anaesthesia and surgery, and dosages of propofol and remifentanil (Table 1A). The same was true for the subgroup $(n=38)$ (Table 1B). Age was the only variable in which the subgroup ( $n=38$, median $50 \mathrm{yr}$, range 36-74 yr) differed from the excluded patients $(n=12$, median $41 \mathrm{yr}$, range $30-52 \mathrm{yr})(t$-test, $P<0.01)$.

Platelet aggregation stimulated with arachidonic acid showed a reduction of activity after diclofenac compared with no change after rofecoxib (mean difference 12\%, 95\% 
Table 2 Coagulation studies before and $4 \mathrm{~h}$ after the first study medication. No significant differences. Thrombelastography TEG ${ }^{\circledR}$ : reaction time (r), coagulation time $(\mathrm{k})$, maximum amplitude (MA), angle $(\alpha)$, lysis at $30 \mathrm{~min}$ (Ly30). Malondialdehyde produced by the platelets after stimulation by arachidonic acid

\begin{tabular}{|c|c|c|c|c|}
\hline & \multicolumn{2}{|l|}{ Rofecoxib } & \multicolumn{2}{|c|}{ Diclofenac } \\
\hline & Predose & Postdose & Predose & Postdose \\
\hline \multicolumn{5}{|l|}{ All patients $(n=50)$} \\
\hline Number $(n)$ & 25 & & 25 & \\
\hline $\mathrm{TEG}^{\circledR} \mathrm{r}(\mathrm{mm})$ & $9(4)$ & $8(3)$ & $8(2)$ & $7(2)$ \\
\hline $\mathrm{TEG}^{\circledR} \mathrm{k}(\mathrm{mm})$ & $3(3)$ & $3(1)$ & $3(1)$ & $3(1)$ \\
\hline $\mathrm{TEG}^{\circledR} \mathrm{MA}(\mathrm{mm})$ & $63(6)$ & $62(6)$ & $62(5)$ & $61(5)$ \\
\hline $\mathrm{TEG}^{\circledR} \alpha\left(^{\circ}\right)$ & $71(9)$ & $74(5)$ & $73(4)$ & $74(4)$ \\
\hline $\mathrm{TEG}^{\circledR} \operatorname{Ly} 30(\%)$ & $2(1)$ & $2(1)$ & $2(1)$ & $2(1)$ \\
\hline Malondialdehyde produced by platelets $\left(\mathrm{mg}\right.$ litre $\left.{ }^{-1}\right)$ & $3.5(1.0)$ & $3.1(1.0)$ & $3.5(1.0)$ & $3.0(1.2)$ \\
\hline \multicolumn{5}{|l|}{ Subgroup $(n=38)$} \\
\hline Number $(n)$ & 19 & & 19 & \\
\hline $\mathrm{TEG}^{\circledR} \mathrm{r}(\mathrm{mm})$ & $9(2)$ & $8(4)$ & $8(2)$ & $7(2)$ \\
\hline $\mathrm{TEG}^{\circledR} \mathrm{k}(\mathrm{mm})$ & $3(1)$ & $3(1)$ & $3(1)$ & $2(1)$ \\
\hline $\mathrm{TEG}^{\circledR} \mathrm{MA}(\mathrm{mm})$ & $65(5)$ & $62(6)$ & $62(5)$ & $61(5)$ \\
\hline $\mathrm{TEG}^{\circledR} \alpha\left(^{\circ}\right)$ & $73(3)$ & $73(6)$ & $74(3)$ & $75(3)$ \\
\hline $\mathrm{TEG}^{\circledR} \operatorname{Ly} 30(\%)$ & $2(1)$ & $2(1)$ & $3(1)$ & $2(1)$ \\
\hline Malondialdehyde produced by platelets (mg litre ${ }^{-1}$ ) & $3.7(1.1)$ & $3.3(0.9)$ & $3.6(0.9)$ & $3.1(1.0)$ \\
\hline
\end{tabular}

Table 3 Blood loss and clinically estimated coagulation. Data are mean (SD). Two-way factorial ANOvA. Estimated coagulation is rated by the surgeon on a five-point scale from no coagulation (1) to increased coagulation (5). Haemoglobin loss is haemoglobin concentration before operation minus the concentration measured on the first postoperative morning. * Rofecoxib vs diclofenac; ${ }^{+}$hysterectomy $v s$ breast surgery

\begin{tabular}{|c|c|c|c|c|c|c|}
\hline \multirow[b]{2}{*}{ All patients $(n=50)$} & \multicolumn{2}{|l|}{ Rofecoxib } & \multicolumn{2}{|l|}{ Diclofenac } & \multirow{2}{*}{$\begin{array}{l}* P v s \\
\text { diclofenac }\end{array}$} & \multirow{2}{*}{$\begin{array}{l}{ }^{+} P \text { vs } \\
\text { breast surgery }\end{array}$} \\
\hline & Hysterectomy & Breast surgery & Hysterectomy & Breast surgery & & \\
\hline$n$ & 13 & 12 & 12 & 13 & & \\
\hline Intraoperative blood loss (ml) & $173(90)^{*^{+}}$ & $83(54)^{*}$ & $279(164)^{+}$ & 235 (127) & $<0.01$ & 0.02 \\
\hline Clinically estimated coagulation (1-5) & $2.9(0.3)$ & $3.0(0.0)$ & $2.6(0.7)$ & $2.8(0.7)$ & NS & NS \\
\hline Haemoglobin loss $\left(\right.$ g litre $\left.^{-1}\right)$ & $16(9)^{*^{+}}$ & $6(7)^{*}$ & $20(11)^{+}$ & $19(7)$ & $<0.01$ & 0.02 \\
\hline Subgroup $(n=38)$ & $\begin{array}{l}\text { Vaginal } \\
\text { hysterectomy }\end{array}$ & $\begin{array}{l}\text { Tumour and } \\
\text { axilla dissection }\end{array}$ & $\begin{array}{l}\text { Vaginal } \\
\text { hysterectomy }\end{array}$ & $\begin{array}{l}\text { Tumour and } \\
\text { axilla dissection }\end{array}$ & & \\
\hline$n$ & 12 & 7 & 10 & 9 & & \\
\hline Intraoperative blood loss (ml) & $179(92)^{*}$ & $117(33)^{*}$ & $295(177)$ & $212(120)$ & 0.01 & NS \\
\hline Clinically estimated coagulation (1-5) & $2.9(0.3)$ & $3.0(0.0)$ & $2.6(0.7)$ & $2.9(0.3)$ & NS & NS \\
\hline Haemoglobin loss $\left(\mathrm{g}\right.$ litre $\left.{ }^{-1}\right)$ & $18(8)^{*+}$ & $6(7)^{*}$ & $21(11)^{+}$ & $18(6)$ & 0.01 & 0.01 \\
\hline
\end{tabular}

CI 22-2, $P=0.02$ ) (Fig. 1). This result remained valid in the subgroup (Fig. 2). The slight increase in aggregation activity in the rofecoxib group from the predose to the postdose measurement (from 47 (32) to 55 (32)\%, difference 9 (37)\%) was statistically not significant ( $t$-test, $P=0.26$ ). No difference in activity was found after platelet aggregation stimulated with collagen or ADP (all patients, Fig. 1; subgroup, Fig. 2). There were no differences between the two drug groups in thrombelastography and MDA values (Table 2). There was an increased estimated blood loss (all patients $(n=50)$, standardized effect size $1.22 \mathrm{SD}, 95 \% \mathrm{CI}$ $0.65-1.78$ SD, $P<0.01$; subgroup $(n=38)$, standardized effect size $0.87 \mathrm{SD}, 95 \%$ CI $0.20-1.53 \mathrm{SD}, P=0.01$ ), and a greater reduction in haemoglobin in the diclofenac compared with the rofecoxib group (all patients $(n=50)$, mean difference $-4 \mathrm{~g} \mathrm{litre}^{-1}, 95 \% \mathrm{CI}-7$ to $-1, P<0.01$; subgroup $(n=38)$, mean difference $-4 \mathrm{~g} \mathrm{litre}^{-1}, 95 \% \mathrm{CI}-7$ to $\left.-1, P=0.01\right)$.
Haemoglobin loss was also greater in the hysterectomy group compared with the breast surgery patients (all patients $(n=50)$, mean difference $-4 \mathrm{~g}$ litre $^{-1}, 95 \% \mathrm{CI}-7$ to -2 , $P<0.01$; subgroup $(n=38)$, mean difference $-4 \mathrm{~g} \operatorname{litre}^{-1}, 95 \%$ CI -7 to $-1, P=0.01)$. No differences were found for clinically estimated coagulation (Table 3 ).

VAS for pain was greater at 1 and $8 \mathrm{~h}$ in the hysterectomy than in the breast surgery group. However, when the subgroup $(n=38)$ was analysed pain readings were similar. No difference in VAS for pain was found between rofecoxib- and diclofenac-treated patients (Table 4). Cumulated doses of nicomorphine were higher in the hysterectomy than in the breast surgery patients for the whole observation period (all patients $(n=50)$, standardized effect size 1.07 SD, 95\% CI 0.50-1.63 SD, $P<0.01$; subgroup $(n=38)$, standardized effect size $0.88 \mathrm{SD}, 95 \%$ CI $0.22-1.54$ SD, $P=0.01$ ), but similar between the rofecoxib and 
Table 4 Pain assessment: VAS $0-100 \mathrm{~mm}$ at the four assessment times. Data are mean (SD). *Hysterectomy $v s$ breast surgery. $P$ values $<0.0125$ are significant after Bonferroni correction

\begin{tabular}{|c|c|c|c|c|c|}
\hline \multirow[t]{2}{*}{ All patients $(n=50)$} & \multicolumn{2}{|c|}{ Hysterectomy } & \multicolumn{2}{|c|}{ Breast surgery } & \multirow[t]{2}{*}{$* P$} \\
\hline & Rofecoxib & Diclofenac & Rofecoxib & Diclofenac & \\
\hline$n$ & 13 & 12 & 12 & 13 & \\
\hline $1 \mathrm{~h}$ after surgery & $45(31)^{*}$ & $61(27)^{*}$ & $29(17)$ & $38(25)$ & 0.009 \\
\hline $4 \mathrm{~h}$ after surgery & $26(19)^{*}$ & $37(20) *$ & $19(14)$ & $19(15)$ & 0.011 \\
\hline $8 \mathrm{~h}$ after study drug & $29(20)^{*}$ & $30(22)^{*}$ & $11(10)$ & $19(17)$ & 0.008 \\
\hline $24 \mathrm{~h}$ after study drug & $18(13)$ & $21(16)$ & $16(19)$ & $15(11)$ & NS \\
\hline \multirow[t]{2}{*}{ Subgroup $(n=38)$} & \multicolumn{2}{|c|}{ Vaginal hysterectomy } & \multicolumn{2}{|c|}{ Tumour and axilla dissection } & \\
\hline & Rofecoxib & Diclofenac & Rofecoxib & Diclofenac & \\
\hline$n$ & 12 & 10 & 7 & 9 & \\
\hline $1 \mathrm{~h}$ after surgery & $44(31)$ & $54(23)$ & $32(17)$ & $35(23)$ & NS \\
\hline $4 \mathrm{~h}$ after surgery & $25(19)$ & $36(21)$ & $17(7)$ & $20(17)$ & NS \\
\hline $8 \mathrm{~h}$ after study drug & $28(21)$ & $29(24)$ & $14(8)$ & $20(17)$ & NS \\
\hline $24 \mathrm{~h}$ after study drug & $20(12)$ & $23(16)$ & $7(5)$ & 19 (11) & NS \\
\hline
\end{tabular}

Table 5 Cumulative doses of nicomorphine (mg) at the four assessment times. Data are mean (SD). Two-way factorial ANOVA. *Hysterectomy $v s$ breast surgery. $P$ values $<0.0125$ are significant after Bonferroni correction

\begin{tabular}{|c|c|c|c|c|c|c|}
\hline \multirow[t]{2}{*}{ All patients $(n=50)$} & \multicolumn{2}{|c|}{ Hysterectomy } & \multicolumn{2}{|c|}{ Breast surgery } & \multirow{2}{*}{$\begin{array}{l}* P \text { vs } \\
\text { breast surgery }\end{array}$} & \multirow[t]{2}{*}{$P$ vs diclofenac } \\
\hline & Rofecoxib & Diclofenac & Rofecoxib & Diclofenac & & \\
\hline$n$ & 13 & 12 & 12 & 13 & & \\
\hline $1 \mathrm{~h}$ postoperative & $12(11)^{*}$ & $11(4)^{*}$ & $4(4)$ & $8(4)$ & $<0.001$ & NS \\
\hline $4 \mathrm{~h}$ postoperative & $20(14)^{*}$ & $19(6)^{*}$ & $6(5)$ & $13(6)$ & $<0.001$ & NS \\
\hline $8 \mathrm{~h}$ after study drug & $22(15)^{*}$ & $20(7)^{*}$ & $6(5)$ & $14(6)$ & $<0.001$ & NS \\
\hline $24 \mathrm{~h}$ after study drug & $32(31)^{*}$ & $29(17)^{*}$ & $9(7)$ & $21(14)$ & 0.001 & NS \\
\hline \multirow[t]{2}{*}{ Subgroup $(n=38)$} & \multicolumn{2}{|c|}{ Vaginal hysterectomy } & \multicolumn{2}{|c|}{ Tumour and axilla dissection } & & \\
\hline & Rofecoxib & Diclofenac & Rofecoxib & Diclofenac & & \\
\hline$n$ & 12 & 10 & 7 & 9 & & \\
\hline $1 \mathrm{~h}$ after surgery & $10(7)^{*}$ & $12(4)^{*}$ & $5(4)$ & $9(5)$ & 0.012 & NS \\
\hline $4 \mathrm{~h}$ postoperative & $17(10)^{*}$ & $19(7)^{*}$ & $7(5)$ & $15(6)$ & 0.003 & NS \\
\hline $8 \mathrm{~h}$ after study drug & $19(11)^{*}$ & $21(8)^{*}$ & $8(5)$ & $15(7)$ & 0.002 & NS \\
\hline $24 \mathrm{~h}$ after study drug & $25(15)^{*}$ & $29(18)^{*}$ & $9(6)$ & $23(14)$ & 0.012 & NS \\
\hline
\end{tabular}

diclofenac groups (Table 5). When the dosages between the individual assessment points were analysed, the breast surgery patients requested less nicomorphine between 1 and $4 \mathrm{~h}$ and between 1 and $8 \mathrm{~h}$ compared with hysterectomy patients. Between the 8 and $24 \mathrm{~h}$ assessments, all groups requested similar dosages of nicomorphine (data not shown). Analgesia over the whole study period was rated $4.1(0.8)$ in the rofecoxib and $3.8(0.8)$ in the diclofenac group on the five-item VRS $(P=0.18)$. Further details are given in Table 6A and $\mathrm{B}$.

Heart rate and blood pressure measurements were similar for all groups. PONV recordings were similar between the drug groups (Table 6A and B). However, there was a reduced requirement for rescue anti-emetic medication in the rofecoxib group (all patients $(n=50)$, standardized effect size $0.72 \mathrm{SD}, 95 \%$ CI $0.16-1.28 \mathrm{SD}, P=0.01$; subgroup $(n=38)$, standardized effect size 0.74 SD, $95 \%$ CI $0.08-1.40$ $\mathrm{SD}, P=0.03)$. The greater satisfaction in the global evaluation of PONV at $24 \mathrm{~h}$ in the rofecoxib group $(P=0.03)$ (all patients) was not maintained when the subgroup was analysed $(P=0.14)$.

One patient in the diclofenac group undergoing breast surgery developed a wound haematoma which required evacuation. No patient developed an increase in serum creatinine of $>9 \mu \mathrm{mol}$ litre $^{-1}$. No differences were found in the course of serum creatinine or cystatin c between the two drug groups (Table 6A and $\mathrm{B}$ ). The same was true for creatinine clearance (hysterectomy patients only). There 
Table 6A Side-effects in the intent-to-treat population $(n=50)$. Data are $n(\%)$ or mean (SD). Two-way factorial ANOVA for continuous and logistic regression for categorical data. $P$ values are for rofecoxib $v s$ diclofenac. 'VRS global evaluation PONV' indicates a verbal rating scale for satisfaction with PONV from 1 (poor) to 5 (excellent) until 8 and $24 \mathrm{~h}$ after the first dose of the study drug. Ramsey scale ${ }^{31}$

\begin{tabular}{|c|c|c|c|}
\hline & Rofecoxib & Diclofenac & $\boldsymbol{P}$ \\
\hline Number $(n)$ & 25 & 25 & \\
\hline Difference (post-preop) in serum creatinine $\left(\mathrm{mmol} \mathrm{litre}{ }^{-1}\right)$ & $-8(7)$ & $-10(7)$ & NS \\
\hline Difference (post-preop) in cystatin c (mg litre $\left.{ }^{-1}\right)$ & $-0.09(0.20)$ & $-0.12(0.28)$ & NS \\
\hline Creatinine clearance $\left(\mathrm{ml} \mathrm{min}^{-1}\right)$ (hysterectomy patients only) & $104(49)$ & $110(29)$ & NS \\
\hline Epigastric pain $(n)$ & $1(4)$ & $3(12)$ & NS \\
\hline Anti-emetic doses administered per patient & $0.5(0.8)^{*}$ & $1.2(1.1)$ & 0.01 \\
\hline Nausea $(n)$ & $3(12)$ & $6(24)$ & NS \\
\hline Vomiting $(n)$ & $2(8)$ & $6(24)$ & NS \\
\hline VRS global evaluation analgesia until $8 \mathrm{~h}(1-5)$ & $3.8(0.9)$ & $3.6(0.8)$ & NS \\
\hline VRS global evaluation analgesia until $24 \mathrm{~h}(1-5)$ & $4.1(0.8)$ & $3.8(0.8)$ & NS \\
\hline VRS global evaluation PONV until 8 h (1-5) & $3.9(0.9)$ & $3.6(0.8)$ & NS \\
\hline VRS global evaluation PONV until $24 \mathrm{~h}$ (1-5) & $4.0(1.0)^{*}$ & $3.3(0.9)$ & 0.03 \\
\hline Wound haematoma $(n)$ & $0(0)$ & $1(4)$ & NS \\
\hline Headache $(n)$ & $5(20)$ & $5(20)$ & NS \\
\hline Sedation: Ramsey scale 2 sleepy $(n)$ & $14(56)$ & $15(60)$ & NS \\
\hline Sedation: Ramsey scale 3 easy arousable $(n)$ & $4(16)$ & $3(12)$ & NS \\
\hline
\end{tabular}

Table 6B Side-effects ( $n=38$ ) (excluding abdominal hysterectomy, minor breast surgery and mastectomy patients). Data are $n(\%)$ or mean (SD). Rofecoxib $v s$ diclofenac. Two-way factorial ANOVA for continuous and logistic regression for categorical data. $P$ values are for rofecoxib $v s$ diclofenac. 'VRS global evaluation PONV' indicates a verbal rating scale for satisfaction with PONV from 1 (poor) to 5 (excellent) until 8 and 24 h after the first dose of the study medicament. Ramsey scale 31

\begin{tabular}{|c|c|c|c|}
\hline & Rofecoxib & Diclofenac & $\boldsymbol{P}$ \\
\hline Number $(n)$ & 19 & 19 & \\
\hline Epigastric pain $(n)$ & $1(5)$ & $2(11)$ & NS \\
\hline Difference (post-preop) serum creatinine (mmol litre ${ }^{-1}$ ) & $-9(7)$ & $-9(7)$ & NS \\
\hline Difference (post-preop) cystatin c (mg litre $\left.{ }^{-1}\right)$ & $-0.11(0.22)$ & $-0.10(0.32)$ & NS \\
\hline Creatinine clearance $(\mathrm{ml} \mathrm{min}-1)$ (hysterectomy patients only) & $101(50)$ & $109(31)$ & NS \\
\hline Anti-emetic doses administered per patient & $0.5(0.9)^{*}$ & $1.3(1.2)$ & 0.03 \\
\hline Nausea $(n)$ & $3(16)$ & $5(26)$ & NS \\
\hline Vomiting $(n)$ & $2(11)$ & $5(26)$ & NS \\
\hline VRS global evaluation analgesia until $8 \mathrm{~h}(1-5)$ & $3.8(1.0)$ & $3.5(0.8)$ & NS \\
\hline VRS global evaluation analgesia until $24 \mathrm{~h}(1-5)$ & $4.1(0.9)$ & $3.8(0.9)$ & NS \\
\hline VRS global evaluation PONV until $8 \mathrm{~h}(1-5)$ & $3.8(0.9)$ & $3.7(0.7)$ & NS \\
\hline VRS global evaluation PONV until $24 \mathrm{~h}$ (1-5) & $3.9(1.2)$ & $3.3(1.0)$ & NS \\
\hline Wound haematoma $(n)$ & $0(0)$ & $1(5)$ & NS \\
\hline Headache $(n)$ & $4(21)$ & $5(26)$ & NS \\
\hline Sedation: Ramsey scale 2 sleepy $(n)$ & $10(53)$ & $10(53)$ & NS \\
\hline Sedation: Ramsey scale 3 easy arousable $(n)$ & $4(21)$ & $2(11)$ & NS \\
\hline
\end{tabular}

were no serious side-effects. However, three (12\%) of the diclofenac and one (4\%) of the rofecoxib patients complained of epigastric pain.

\section{Discussion}

This study compared the effects on platelet function, bleeding parameters, safety, and analgesic efficacy of a single preoperative oral dose of the COX-2-specific inhibitor rofecoxib $50 \mathrm{mg} v s$ three oral doses of the COXnon-selective NSAID diclofenac sodium $50 \mathrm{mg}$. Rofecoxib compromised platelet aggregation stimulated with arachidonic acid less than did diclofenac. The estimated surgical blood loss was less and the decrease in haemoglobin concentration until the postoperative morning was smaller in the rofecoxib than in the diclofenac group. Ratings of analgesia and the use of rescue opioids were similar in the two drug groups. In addition, the use of anti-emetic medication was reduced in the rofecoxib group.

We assessed the effect of the two study drugs on coagulation by platelet aggregation stimulated with arachidonic acid, the primary endpoint of the study. This test is sensitive to the inhibition of the COX-1 by NSAIDs. ${ }^{6}$ While non-selective NSAIDs such as diclofenac inhibit both COX-1 and COX-2 to a varying degree, COX-2-selective drugs predominantly block the latter enzyme only. ${ }^{12} 13$ Although the study hypothesis (that rofecoxib possesses a smaller inhibitory effect on COX-1 compared with diclofenac) was confirmed, the decrease in aggregation activity in the diclofenac group was smaller than expected ${ }^{14}$ but was in accordance with the measurements of Van Heck and colleagues. ${ }^{15}$ This might have been because the timing 
of the coagulation study $4 \mathrm{~h}$ after the first dose was different from the expected time of the peak plasma concentrations of the drug, ${ }^{16} 17$ as the first doses of both study drugs were given immediately before anaesthesia induction, and absorption of the drugs might have been slowed by i.v. opioids. ${ }^{18}$ A further reason might be that the full effect on the inhibition of aggregation is reached only after several doses of an NSAID. ${ }^{6}$ Surprisingly, the MDA content of platelets was not different between the two study groups, although MDA is very sensitive to COX-1 inhibition of platelets. ${ }^{9}$ It is likely that this could also be due to the timing of the drug intake and altered absorption. In addition, there was no difference between the two drug groups with respect to thrombelastograph analysis. However, this is not very sensitive to the effects of NSAIDs. ${ }^{19}$

Concerns have been raised by Mukherjee and colleagues, ${ }^{20}$ who found an increased incidence of thrombotic cardiovascular adverse events (TCAE) in the rofecoxib 50 mg daily group when reanalysing the VIGOR trial. ${ }^{7}$ However, in the VIGOR trial rofecoxib was compared with naproxen $1000 \mathrm{mg}$ daily, an NSAID with a strong inhibitory effect on platelet COX-1. ${ }^{15}$ When rofecoxib was compared with placebo or non-selective NSAIDs in $>5000$ patients, no difference in the incidence of TCAE was found. $^{21}$ No TCAE was recorded in our patients and the small numerical rise in platelet aggregation stimulated with arachidonic acid after rofecoxib (Fig. 1) is not statistically significant. Although no signs of hypercoagulability were observed in this study, the study population was too small to definitively exclude slight postoperative hypercoagulability.

Increased blood loss has been observed when preoperative non-selective COX inhibitors have been compared with placebo $^{4}$ or paracetamol. ${ }^{22}$ Interestingly, in this study a greater estimated intraoperative blood loss and increased loss of haemoglobin until $24 \mathrm{~h}$ was also observed in the conventional NSAID group. The reason for this may well be the reduced production of the coagulation activator thromboxane $\mathrm{B}_{2}$, which is biosynthesized by COX-1. ${ }^{23}$

The dose of rofecoxib used was based on previous experience in the perioperative setting. ${ }^{24-26}$ Because rofecoxib has a terminal half-life of $17 \mathrm{~h},{ }^{16}$ a single oral dose can be expected to be active for almost $24 \mathrm{~h}$. The terminal half-life of diclofenac is $2 \mathrm{~h}$ and this drug must be given 8-hourly if it is to stay effective. It has been used widely in similar doses in the surgical setting. ${ }^{12728}$ Thus, our main questions were: (i) is rofecoxib as effective as diclofenac, and (ii) does its effect fade after $8 \mathrm{~h}$, after which the diclofenac group gets additional drug doses? The cumulative consumption of the rescue analgesic nicomorphine was lower in the breast surgery group than in the hysterectomy group throughout the whole study period and there was a trend for a lower consumption of nicomorphine in the rofecoxib group than in the diclofenac group. In addition, there was no increased need for rescue analgesics in the rofecoxib group in the period from 8 until $24 \mathrm{~h}$. In this period the patients in the diclofenac group received two additional doses of the respective NSAID while the rofecoxib group received two placebos only. However, satisfaction with pain treatment and readings of pain assessment were not different between the two groups.

Recent work has clarified some questions regarding the renal effects of selective COX-2 inhibitors. Prostacyclin, synthesized in the kidney by COX-2, seems to play an important role in the control of sodium reabsorption. When prostacylin is reduced due to the inhibition of COX-2 by NSAIDs or selective COX-2 inhibitors, this may lead to oedema, hypertension and a reduction in glomerular filtration rate, ${ }^{29}$ and the incidence of renal failure provoked by COX-2 inhibitors seems to be equal to that associated with conventional NSAIDs. ${ }^{30}$ However, in our well-hydrated patients, who received approximately 2.5 litres of Ringer's lactate per day, serum markers of glomerular filtration fell between the pre- and postoperative values, and in the hysterectomy patients measured serum creatinine filtration rate remained in the higher normal range even when normalized to $1.73 \mathrm{~m}^{2}$ of body surface $\left(106 \mathrm{ml} \mathrm{min}^{-1}\right.$ $1.73 \mathrm{~m}^{-2}$ ). This was true for both drug groups.

Besides analgesia, PONV represents an important determinant of perioperative patient satisfaction. Although there was no difference in the number of episodes of nausea or vomiting, the use of anti-emetics was smaller in the rofecoxib group. This was also true for the subgroup but the greater satisfaction in the rofecoxib group with respect to PONV at $24 \mathrm{~h}$ in all patients was not maintained in the subgroup.

Regarding gastrointestinal side-effects, the population studied were a relatively healthy group, because a history of upper gastrointestinal pathology or past problems with oral NSAIDs constituted a criterion for exclusion from the study. Despite this, one subject in the rofecoxib group and three patients in the diclofenac group complained of upper abdominal discomfort. A postoperative haemorrhage required evacuation in one patient in the diclofenac group. There were no other severe side-effects.

\section{Acknowledgement}

The study was supported in part by MSD (Glattbrugg, Switzerland).

\section{References}

I Bamber MJ, Tweedie IE, Breeze C, Williams NE. Premedication with controlled release diclofenac sodium reduces postoperative pain after minor gynaecological surgery. Eur J Anaesthesiol 1997; 14: 42I-7

2 Perttunen K, Nilsson E, Kalso E. I.V. diclofenac and ketorolac for pain after thoracoscopic surgery. Br J Anaesth 1999; 82: 22I-7

3 Lee A, Cooper MC, Craig JC, Knight JF, Keneally JP. Effects of nonsteroidal anti-inflammatory drugs on post-operative renal function in normal adults (Cochrane Review). Cochrane Database Syst Rev 200I; 2

4 Gabbott DA, Cohen AM, Mayor AH, Niemiro LA, Thomas TA. The influence of timing of ketorolac administration on post- 
operative analgesic requirements following total abdominal hysterectomy. Eur J Anaesthesiol 1997; 14: 610-5

5 Strom BL, Berlin JA, Kinman JL, et al. Parenteral ketorolac and risk of gastrointestinal and operative site bleeding. A postmarketing surveillance study. JAMA 1996; 275: 376-82

6 Leese PT, Hubbard RC, Karim A, Isakson PC, Yu SS, Geis GS. Effects of celecoxib, a novel cyclooxygenase-2 inhibitor, on platelet function in healthy adults: a randomized, controlled trial. J Clin Pharmacol 2000; 40: 124-32

7 Bombardier C, Laine L, Reicin A, et al. Comparison of upper gastrointestinal toxicity of rofecoxib and naproxen in patients with rheumatoid arthritis. VIGOR Study Group. $N$ Engl J Med 2000; 343: I520-8

8 Mehlisch DR, Fulmer RI. A crossover comparison of bromfenac sodium, naproxen sodium, and placebo for relief of pain from primary dysmenorrhea. J Womens Health 1997; 6: 83-92

9 Raineri-Gerber I, von Felten A. Inhibition of thrombocyte function by non-steroidal anti-rheumatic agents: a comparative study between diclofenac, acemetacin, mefenamic acid and ibuprofen. Schweiz Med Wochenschr 199I; I 2 I: 783-7

10 Camenzind V, Bombeli T, Seifert B, et al. Citrate storage affects. Thrombelastograph analysis. Anesthesiology 2000; 92: I242-9

I I Laisalmi M, Teppo AM, Koivusalo AM, Honkanen E, Valta P, Lindgren $L$. The effect of ketorolac and sevoflurane anesthesia on renal glomerular and tubular function. Anesth Analg 200I; 93 : 1210-3

I2 Riendeau D, Charleson S, Cromlish W, Mancini JA, Wong E, Guay J. Comparison of the cyclooxygenase-I inhibitory properties of nonsteroidal anti-inflammatory drugs (NSAIDs) and selective COX-2 inhibitors, using sensitive microsomal and platelet assays. Can J Physiol Pharmacol 1997; 75: 1088-95

13 Chan CC, Boyce S, Brideau C, et al. Rofecoxib [Vioxx, MK-0966; 4-(4'-methylsulfonylphenyl)-3-phenyl-2-(5H)- furanone]: a potent and orally active cyclooxygenase-2 inhibitor. Pharmacological and biochemical profiles. J Pharmacol Exp Ther 1999; 290: $551-60$

14 Leese PT, Talwalker S, Kent JD, Recker DP. Valdecoxib does not impair platelet function. Am J Emerg Med 2002; 20: 275-8I

15 VanHecken A, Schwartz JI, Depre M, et al. Comparative inhibitory activity of rofecoxib, meloxicam, diclofenac, ibuprofen, and naproxen on COX-2 versus COX-I in healthy volunteers. J Clin Pharmacol 2000; 40: I 109-20

16 Merck \& Co. Inc. Vioxx ${ }^{\text {TM }}$ prescribing information. Whitehouse Station, New Jersey: Merck \& Co., 1998.

17 Kendall MJ, Thornhill DP, Willis JV. Factors affecting the pharmacokinetics of diclofenac sodium (Voltarol). Rheumatol Rehabil 1979; Suppl 2: 38-46

18 Yuan CS, Foss JF, O'Connor M, Roizen MF, Moss J. Effects of low-dose morphine on gastric emptying in healthy volunteers. J Clin Pharmacol 1998; 38: 1017-20

19 Reinhart DJ, Latson TW, Whitten CW, Klein KW, Allison PM, Patel M. Influence of ketorolac tromethamine on clot elastic strength in humans as assessed by thromboelastography. J Clin Anesth 1993; 5: 216-20

20 Mukherjee D, Nissen SE, Topol EJ. Risk of cardiovascular events associated with selective COX-2 inhibitors. JAMA 200I; 286: 954-9

21 Reicin AS, Shapiro D, Sperling RS, Barr E, Yu Q. Comparison of cardiovascular thrombotic events in patients with osteoarthritis treated with rofecoxib versus nonselective nonsteroidal antiinflammatory drugs (ibuprofen, diclofenac, and nabumetone). Am J Cardiol 2002; 89: 204-9

22 Schmidt A, Bjorkman S, Akeson J. Preoperative rectal diclofenac versus paracetamol for tonsillectomy: effects on pain and blood loss. Acta Anaesthesiol Scand 200I; 45: 48-52

23 Catella-Lawson F, McAdam B, Morrison BW, et al. Effects of specific inhibition of cyclooxygenase-2 on sodium balance, hemodynamics, and vasoactive eicosanoids. J Pharmacol Exp Ther 1999; 289: 735-4I

24 Reuben SS, Connelly NR. Postoperative analgesic effects of celecoxib or rofecoxib after spinal fusion surgery. Anesth Analg 2000; 91: $1221-5$

25 Reuben SS, Fingeroth R, Krushell R, Maciolek H. Evaluation of the safety and efficacy of the perioperative administration of rofecoxib for total knee arthroplasty. J Arthroplasty 2002; 17: 2631

26 Watcha MF, Issioui T, Klein KW, White PF. Costs and effectiveness of rofecoxib, celecoxib, and acetaminophen for preventing pain after ambulatory otolaryngologic surgery. Anesth Analg 2003; 96: 987-94

27 Fredman B, Jedeikin R, Olsfanger D, Aronheim M. The opioidsparing effect of diclofenac sodium in outpatient extracorporeal shock wave lithotripsy (ESWL). J Clin Anesth 1993; 5: 14I-4

28 Rautoma P, Santanen U, Avela R, Luurila H, Perhoniemi V, Erkola O. Diclofenac premedication but not intra-articular ropivacaine alleviates pain following day-case knee arthroscopy. Can J Anaesth 2000; 47: 220-4

29 Niccoli L, Bellino S, Cantini F. Renal tolerability of three commonly employed non-steroidal anti-inflammatory drugs in elderly patients with osteoarthritis. Clin Exp Rheumatol 2002; 20: 20I-7

30 Ahmad SR, Kortepeter C, Brinker A, Chen M, Beitz J. Renal failure associated with the use of celecoxib and rofecoxib. Drug Saf 2002; 25: 537-44

31 Ramsay MA, Savege TM, Simpson BR, Goodwin R. Controlled sedation with alphaxalone-alphadolone. $B r$ Med J 1974; 2: 656-9 